IOS Press

\title{
Editorial
}

\section{Addressing significant gaps in the information requested for evidence-based sub-national and sub-regional policy making: Using new methods and new data sources}

\author{
Klaus Trutzel ${ }^{\mathrm{a}, *}$ and Teodora Brandmüller ${ }^{\mathrm{b}}$ \\ ${ }^{a}$ Bureau for Statistics and Urban Research, City of Nuremberg, Germany \\ ${ }^{\mathrm{b}}$ Eurostat and Chair of SCORUS
}

Life is local. Recognising the fact that local living conditions and perspectives vary considerably, is the first step in designing development policies on the global, European, national, regional and municipal level. Specific and comparable local and regional information is the decisive factor for effective policies.

The Lisbon Memorandum on Indicators for decision making and monitoring ${ }^{1}$ has been adopted by the European Statistical System Committee in 2015. The Memorandum acknowledged the importance of disaggregation for many indicators along territorial characteristics and recommended to work actively on closing data gaps, for example in the context of the United Nations Sustainable Development Goals (UN SDGs) in close co-operation with partners at UN level and with the OECD. The Memorandum also draws attention to the challenges and opportunities of using a combination of new (Big Data, geographical information, etc) and traditional data sources within solid statistical frame-

\footnotetext{
*Corresponding author: Klaus Trutzel, Bureau for Statistics and Urban Research, City of Nuremberg, Germany. E-mail: kum.trutzel @ t-online.de.

${ }^{1}$ http://ec.europa.eu/eurostat/documents/7330775/7339365/ DGINS+memorandum+2015/40e90649-d058-47e1-8e98$6 c 5 a 94453931$.
}

works and models to produce fit for purpose indicators. Last but not least, the Memorandum commits to promote exchange of experience on using statistical indicators to convey knowledge and understanding.

This commitment has been fully met, at the conference held in Lisbon in 2016 aimed to address the development of regional and urban statistics, the challenges and opportunities in the context of cross-cutting issues that have been put forward in European and global agendas. It was jointly organized by SCORUS the Statistical Office of Portugal (INE), Eurostat and OECD. SCORUS is the network for regional and urban statistics managed by a standing committee under the umbrella of the International Association for Official Statistics (IAOS). This was the 28th conference in a series of biennial international SCORUS conferences. The Conference was able to gather more than 100 participants from both national and international organizations, bringing together professionals from National Statistical Institutes, public administration agencies, universities and reference research centres.

During the 2016 conference, under the motto "Indicators for territorial policies: closing data gaps by using traditional and new sources and methods" participants reported on their experience, presented results 
achieved with new data sources and new methods and showed the progress in their fields of activities.

We are most delighted to invite you to explore this special issue of the Statistical Journal of the International Association for Official Statistics featuring urban, regional and small area statistics. A selection of the papers presented at the conference appears in this volume and some of the presentations given are mentioned in this introduction. However, due to limitations in length and the very rich content of the conference we can not mention all contribution. We encourage you to explore all papers and presentations given at the 2016 conference together with the documents of previous conferences published on the www.scorus.org website.

In the past years international and national statistical authorities have made great progress in the production and dissemination of territorial statistics to meet the growing demand for territorial indicators to support public policies and related research activities. The use of new data sources and advances in information technology among others (Big Data, open data, geographical information, etc.) opened new possibilities in this domain.

As a means of drawing attention to these recent developments, Eurostat released the publication "Urban Europe - statistics on cities, towns and suburbs" [1] presenting a wide range of indicators on urban territories and complementary information on rural areas. The publication tells statistical stories. It uses various territorial units ranging from the 1 square $\mathrm{km}$ grid, through local administrative units, to functional labour market areas illustrating the different possibilities to calculate territorial indicators. Some of the analyses presented in the publication is based on Big Data, geographical information or a combination of these two. The publication has been featured in the opening session of the conference by Mr. Gunter Schäfer from Eurostat [2].

Despite the progress, some challenges remain. In his introductory presentation at the conference, Mr. Klaus Trutzel stressed the importance of comparability when describing and analysing territorial units of different population size by indicators related to this population size, like the share of senior citizens, unemployment rates or proportion of single person households [3]. Comparing German collections of sub-city data of different granularity, he showed that the number of territorial units with high concentrations of certain population groups vary with the size levels of these collections. Clusters of population groups of equal size showing up in the indicator values of small territorial units may be hidden in the averages of larger units. Since size matters, this kind of indicators should be used only if the territorial units under observation are of approximately equal population size. This is rarely the case when comparing administrative or similarly defined territorial units.

The relevance of the size and delimitation of territorial units, known as the "modifiable area unit problem" (MAUP) was also pointed out by Ms Elsa Soares from Statistics Portugal reporting on the delimitation of labour market areas in Portugal defined as functional areas based on the territorial distribution of labour demand and supply [4].

The functional approach to territorial breakdowns is gaining importance as shown in the paper presented by Ms Luisa Franconi [5]. The Italian labour market areas defined by ISTAT have been long recognised as meaningful territorial units which are relevant for regional policies and local governments. Recently, new opportunities are offered to build comparable European Labour Market Areas. The power of this geography as illustrated by the Italian case is the ability to differentiate zones having specific characteristics and to serve as comparable territorial units for analyzing the socio-economic situation and evolution.

The presentation given by Ms Cláudia Costa focused on the monitoring of the population health situation at regional level. Her paper identifies two main challenges [6]. Firstly, there is a gap between indicators considered relevant by policy makers and the indicators provided through official data sources. Secondly, the indicators provided through official sources sometimes lack the temporal or geographical detail needed.

One way to close data gaps and provide relevant territorial indicators for policy makers is to achieve more territorial details and flexibility. Many presentations report on using administrative registers as new or additional sources to achieve this. Cooperation with municipal and other public administrations is frequently based on formal agreements, like in France, as reported e.g. by Mr. Luc Brière [7] and in England and Wales, as reported by Mr. Bill South [8] or on specific laws, like in Portugal, where INE can evaluate municipal building and construction permits in combination with the stock of buildings and dwellings from the latest census. Administrative registers and data from administrative processes play a prominent role, not only because they may close potential gaps in official statistics; they are also of particular interest because they are mostly address-based and thus enable territorial aggregates for any small scale units that the user may request and on which the cooperating authorities have agreed. 
This feature has been illustrated by Mr. Bill South, in his paper on House Price Statistics for Small Areas for England and Wales [8]. The statistics are produced using administrative data obtained from the government agency responsible for maintaining the record of land ownership. The smallest territorial level covered by the resulting data set are the so-called middle layer super output areas (areas with a population of approximately 7500 people). This creates such flexibility that the dataset can be adapted to give new insights to new geographies like local areas, major towns, etc.

Similarly, very interesting new insight have been learned about income poverty and inequality at local level in France using FILOSOFI ("FIchier LOcalisé SOcial et FIscal", the "Social and Tax Localised Database") [7]. As described in the paper of Luc Brière the database was created by merging data from the tax authorities and data from social benefits funds. Confidentiality is very important, especially for income data on small territories. Therefore special attention was given to implement rules to prevent the risk of disclosure and to assure the strict confidentiality of the data.

By using these administrative data sources that provide the intended territorial differentiation, the analysts are confronted with several issues. Statisticians have experience and competence in assuring confidentiality. However, there are some specific issues due to the fact that these sources follow non-statistical rules determined by the processes they originate from. They hardly ever follow the requirements of official statistics. If they are to be combined with data from official statistics, they need to be processed and harmonized by statistical methods in order to establish comparability regarding their content, geography and time references. The description of this process is a relevant part of the papers presented here.

Another possibility to close data gaps is to enhance sample surveys. Using survey data for territorial policies has some specific challenges compared to administrative data. Sample sizes are limited, thus the territorial detail of the indicators calculated is limited as well. The paper presented by Ms Eduarda Góis focused on this challenge [9]. The objective of her project is to design a sample for the EU Social Income and Living Condition (EU SILC) survey which would be representative at the regional (NUTS 2) level in 2018. This target will be accomplished by increasing the sample size and modifying the sample allocation. The allocation was recalculated to achieve regional representativeness compatible to the precision requirements agreed at EU level.
After focusing on different territorial aspects, different domains, different sources and their challenges, to conclude, we recommend you to read the contribution on how all these issues have been successfully dealt with in Poland written by Ms Dominika Rogalńska [10]. The paper shares their experience of building a database application used for monitoring development policies. It integrates indicators derived from different sources which are used for monitoring the policy implementation at different levels including the regional level.

We would like to express our gratitude to Ms lda de Caetano Carvalho and Ms Helena Cordeiro the President and the Vice-President of Statistics Portugal for hosting the conference and for their warm welcome and hospitality. We would like to say a special thanks to the local organizing and programme committee, $\mathrm{Mr}$. Francisco Vala, Ms Cátia Nunes from Statistics Portugal and Mr. Eric Gonnard from OECD. Of course we are grateful to all participants, speakers, session chairs for their contributions and for the fruitful discussions. We wish you an enjoyable read!

\section{References}

[1] Urban Europe statistics on cities, towns and suburbs. Luxembourg: Publications Office of the European Union; 2016. [cited 31 January 2017]. Available from: http://ec.europa.eu/ eurostat/en/web/products-statistical-books/-/KS-01-16-691.

[2] G. Schäfer, Statistics on cities, towns and suburbs supporting urban policies. SCORUS conference on Indicators for territorial policies: closing data gaps by using traditional and new sources and methods; 2016 June; Lisbon (Portugal). [cited 31 January 2017]. Available from: http://scorus.org/index.php/ conferences/2016-2/scorus-conference-in-lisbon-portugal/.

[3] K. Trutzel, Closing gaps of understanding in territorial comparisons. SCORUS conference on Indicators for territorial policies: closing data gaps by using traditional and new sources and methods; 2016 June; Lisbon (Portugal). [cited 31 January 2017]. Available from: http://scorus.org/index.php/ conferences/2016-2/scorus-conference-in-lisbon-portugal/.

[4] E. Soares and R. Figueiredo, Labour Market Areas: The Portuguese case. SCORUS conference on Indicators for territorial policies: closing data gaps by using traditional and new sources and methods; 2016 June; Lisbon (Portugal). [cited 31 January 2017]. Available from: http://scorus.org/index.php/ conferences/2016-2/scorus-conference-in-lisbon-portugal/.

[5] L. Franconi, S. Cruciani, M. D'Alò and D. Ichim, Labour Market Areas for territorial policies: potentials for a European approach. SCORUS conference on Indicators for territorial policies: closing data gaps by using traditional and new sources and methods; 2016 June; Lisbon (Portugal). [cited 31 January 2017]. Available from: http://scorus.org/index.php/ conferences/2016-2/scorus-conference-in-lisbon-portugal/.

[6] C. Costa, I. Stefanik and Â. Freitas, Challenges and constraints measuring and monitoring Population Health of European regions. SCORUS conference on Indicators for terri- 
torial policies: closing data gaps by using traditional and new sources and methods; 2016 June; Lisbon (Portugal). [cited 31 January 2017]. Available from: http://scorus.org/index.php/ conferences/2016-2/scorus-conference-in-lisbon-portugal/.

[7] L. Brière, FILOSOFI, a new administrative source on disposable income and poverty at a local level in France. SCORUS conference on Indicators for territorial policies: closing data gaps by using traditional and new sources and methods; 2016 June; Lisbon (Portugal). [cited 31 January 2017]. Available from: http://scorus.org/index.php/conferences/2016-2/scorus -conference-in-lisbon-portugal/.

[8] B. South, House price statistics for small areas - using admin data to give new insights. SCORUS conference on Indicator for territorial policies: closing data gaps by using traditional and new sources and methods; 2016 June; Lisbon (Portugal). [cited 31 January 2017]. Available from: http://scorus.org/ index.php/conferences/2016-2/scorus-conference-in-lisbonportugal/.
[9] E. Góis, The way to NUTS 2 regional estimates in the Portuguese EU-SILC survey. SCORUS conference on Indicators for territorial policies: closing data gaps by using traditional and new sources and methods; 2016 June; Lisbon (Portugal). [cited 31 January 2017]. Available from: http://scorus.org/ index.php/conferences/2016-2/scorus-conference-in-lisbonportugal/.

[10] D. Rogalńska, Public statistics for programming and monitoring cohesion policy - Polish experience with the STRATEG system. SCORUS conference on Indicators for territorial policies: closing data gaps by using traditional and new sources and methods; 2016 June; Lisbon (Portugal). [cited 31 January 2017]. Available from: http://scorus.org/index.php/conferen ces/2016-2/scorus-conference-in-lisbon-portugal/. 